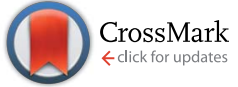

Cite this: RSC Adv., 2017, 7, 11601

\title{
A novel antibacterial cellulose based biomaterial for hernia mesh applications $\uparrow$
}

\author{
Sa Liu, ${ }^{\text {ab }}$ Minglei Chu, ${ }^{\text {ab }}$ Yongjun Zhu, ${ }^{\text {ab }}$ Lifeng Li, ${ }^{\text {ab }}$ Lin Wang, ${ }^{\text {ab Huichang Gao*c }}$ \\ and Li Ren*ab
}

A novel bacterial cellulose/collagen-hydroxypropyltrimethyl ammonium chloride chitosan composite $(\mathrm{BCC}-\mathrm{H})$, as an ideal artificial hernia mesh, was synthesized by combining solution impregnation with the EDC/NHS chemical crosslinking method. Scanning electron microscopy was used to examine the morphology of the bacterial cellulose/collagen (BCC) and $\mathrm{BCC}-\mathrm{H}$ composites. Infrared spectroscopy demonstrated that collagen and hydroxypropyltrimethyl ammonium chloride chitosan (HACC) were incorporated into the bacterial cellulose network successfully. Mechanical testing of the materials showed that the addition of HACC made the tensile strength decrease while the elongation at break was increased. Antibacterial assessment of the $\mathrm{BCC}-\mathrm{H}$ composites revealed distinct growth inhibition against Escherichia coli and Staphylococcus aureus. In vitro cell experiments confirmed that the BCC-H composites had low cytotoxicity and good biocompatibility.

Received 2nd November 2016 Accepted 23rd January 2017

DOI: 10.1039/c6ra26216c

rsc.li/rsc-advances types of materials have already been used for several applications, such as wound dressing, artificial skin for severe burns, artificial blood vessels and tissue engineering scaffolds. ${ }^{17-20}$ However, the non-antibacterial ability of BC confines its further application as an implantable biomaterial.

Hydroxypropyltrimethyl ammonium chloride chitosan (HACC) is a derivative of chitosan, which is known to be a natural antibacterial agent. ${ }^{21,22}$ Furthermore, HACC has better antibacterial properties than chitosan due to its positive charge. $^{23,24}$ Meanwhile, the introduction of a quaternary ammonium group into chitosan can enhance the hydratability, resulting in better moisture absorption and moisture retention. ${ }^{25,26}$ However, the positive charge on the surface of HACC has an intense electrostatic interaction with negatively charged cells, causing cytotoxicity to a certain degree. Therefore, to address this issue, collagen, as the main protein of animals and which is widely used in the biomedical field, is introduced to improve the biocompatibility and bioactivity of the composites..$^{27,28}$

In this study, we tried to fabricate a novel antibacterial cellulose based biomaterial for hernia mesh applications. An EDC/NHS chemical crosslinking method is used to prepare the BCC composite. A solution impregnation method is used to incorporate HACC into BCC to enhance its antibacterial properties. Scanning electron microscopy and infrared spectroscopy were used to examine the morphology of the BCC composites and to ensure the successful incorporation of collagen and HACC into the bacterial cellulose network. Mechanical testing of the materials was also performed to ensure that the mechanical properties of the hernia mesh are suitable. Furthermore, antibacterial assessment and an in vitro cell

\footnotetext{
${ }^{a}$ School of Materials Science and Engineering, South China University of Technology, Guangzhou 510641, China. E-mail: psrenli@163.com

${ }^{b}$ National Engineering Research Centre for Tissue Restoration and Reconstruction, Guangzhou 510006, China

${ }^{c}$ School of Medicine, South China University of Technology, Guangzhou 510006, China $\dagger$ Electronic supplementary information (ESI) available. See DOI: $10.1039 /$ c6ra26216c
} 
experiment of the $\mathrm{BCC}-\mathrm{H}$ composites were conducted to confirm the antibacterial properties and cell biocompatibility. It is expected that the novel composites will have great potential for hernia mesh applications.

\section{Experimental section}

\section{Materials}

Bacterial peptone, bacto-agar and yeast extract were purchased from Guangdong Huankai Microbial Technology Limited Company (Guangzhou, China). $\mathrm{MgSO}_{4}$ and $\mathrm{CaCl}_{2}$ with purities higher than $99.9 \%$ were purchased from Tianjin Chemical Factory (Tianjin, China). 1-(3-Dimethylaminopropyl)-3ethylcarbodiimide hydrochloride $(\mathrm{EDC} \cdot \mathrm{HCl})$ and $N$-hydroxysuccinimide (NHS) with purities higher than $99.9 \%$ were provided by GL Biochem Ltd. (Shanghai, China). 2-Hydroxypropyltrimethyl ammonium chloride chitosan (HACC, Medical Grade) was provided by Zhejiang Aoxing-biology Ltd. (Taizhou, China). Acetic acid, ethyl alcohol (absolute), sodium hydroxide, sodium dodecyl sulfate and glucose (AR) were provided by Sinopharm Chemical Reagent Co., Ltd. (Shanghai, China). A dialysis bag (MWCO8000-1.44w) was provided by Guangzhou Qiyun biotechnology Ltd. (Guangzhou, China). Collagen (beef tendon, Type 1) was provided by Guangzhou Huameikanglian Biotechnology Ltd. (Guangzhou, China). Acetobacter xylinus was purchased from ATCC (USA).

\section{Preparation and purification of $\mathrm{BC}$}

Acetobacter xylinus was inoculated on sterilized medium, which consisted of fermented coconut juice, $1 \%$ yeast extract powder, $0.6 \%$ bacto-peptone, $0.02 \% \mathrm{MgSO}_{4}, 0.01 \% \mathrm{CaCl}_{2}$ and $2 \%$ glucose. Subsequently, the bacterium was cultured statically to get a bacterial cellulose membrane. Thereafter, the $\mathrm{BC}$ membrane was purified by sequential washing steps of tap water, distilled water, $0.1 \mathrm{M} \mathrm{NaOH}, 2 \%$ sodium dodecyl sulfate and distilled water, in that order. The purified $\mathrm{BC}$ was cut into $3 \mathrm{~cm} \times 4 \mathrm{~cm}$ slices and stored in deionized water at a low temperature to prevent drying.

\section{Preparation of BCC and BCC-H composites}

The prepared BC pieces were immersed in a $0.25 \%(\mathrm{w} / \mathrm{w})$ collagen solution and gently rocked for $24 \mathrm{~h}$ in a shaking table. Then, the BC pieces were crosslinked in a $0.1 \%$ EDC/NHS (EDC : NHS $=2: 1$ ) solution for $24 \mathrm{~h}$ at $4{ }^{\circ} \mathrm{C}$. The pieces were afterwards washed with distilled water, and a 24 hour dialysis followed. The water was changed every $12 \mathrm{~h}$. The prepared BCC composites were dried at $37{ }^{\circ} \mathrm{C}$ for $24 \mathrm{~h}$. Subsequently, $0.5 \%$, $0.25 \%$ and $1.0 \%(\mathrm{w} / \mathrm{v})$ HACC solutions were prepared. The prepared BCC composites were immersed in the $0.5 \%, 0.25 \%$ and $1.0 \%$ HACC solutions for $12 \mathrm{~h}$, respectively. Finally, the prepared BCC-H materials were dried at $37{ }^{\circ} \mathrm{C}$ and named as BCC $-0.25 \mathrm{H}, \mathrm{BCC}-0.5 \mathrm{H}$ and $\mathrm{BCC}-1.0 \mathrm{H}$, respectively.

\section{Infrared analysis of the BCC-H composites}

The chemical structures of the BCC-H composites were characterized using Fourier transform-infrared spectroscopy (FTIR,
Nicolet, USA) in the range between 3800 and $800 \mathrm{~cm}^{-1}$ at room temperature. In order to do so, the materials were lyophilized and ground into powder and then combined with $\mathrm{KBr}$ to prepare a disk for observation.

\section{Morphology of the BCC-H composites}

The morphologies of the prepared BCC-H materials were characterized using scanning electron microscopy (SEM, EVO18, Germany). Prior to the SEM observation, the materials were lyophilized and coated with an ultrathin layer of gold by an ion sputter.

\section{Water absorptivity characterization}

The equilibrated water absorptivity of the BCC-H materials was measured. First, the weight $\left(M_{0}\right)$ of the BCC and BCC-H materials treated under different conditions was measured. The specimens were then immersed in a phosphate-buffered saline solution ( $\mathrm{PBS}, \mathrm{pH}=7.4$ ) at $37^{\circ} \mathrm{C}$. After determined time points, the specimens were removed and their weight $\left(M_{t}\right)$ was measured. The water content ratio $(W \%)$ was calculated according to the following equation: $W \%=\left(M_{t}-M_{0}\right) / M_{t} \times$ $100 \%$.

\section{Mechanical properties}

The mechanical properties were determined using a dynamic biomechanical testing machine (Bose ELF3200, USA). In brief, the specimens were cut into dumbbell-shaped sticks with sizes of $35 \mathrm{~mm} \times 5 \mathrm{~mm}$. The sticks were then stretched at a crosshead speed of $100 \mathrm{~mm} \mathrm{~min}^{-1}$ to reach a constant strain rate. Five parallel samples were used for each group. The tensile strength $(\delta)$ and elongation at break were calculated according to the following equations:

$$
\begin{gathered}
\text { Tensile strength } \delta=F /(a \times b) \\
\text { Elongation at break }=\Delta L / L \times 100 \%
\end{gathered}
$$

where $F$ represents the breaking load, $a$ is the width of the stick, $b$ is the thickness of the stick, $\Delta L$ is the elongation of the stick when it fractures, and $L$ is the original length of the stick.

\section{Antibacterial assessment}

The antibacterial properties of $\mathrm{BC}, \mathrm{BCC}$ and $\mathrm{BCC}-\mathrm{H}$ were analyzed against Escherichia coli as a Gram-negative bacterium and Staphylococcus aureus as a Gram-positive bacterium, using the colony forming count method..$^{29-31}$ E. coli and S. aureus were provided by the Guangzhou industrial microbiology testing center (Guangzhou, China). Both types of bacteria were cultivated in a nutrient broth. The composites were placed in 24-well culture plates and inoculated with $750 \mu \mathrm{L}$ of bacterial suspension $\left(1.0 \times 10^{8} \mathrm{cfu} \mathrm{mL}^{-1}\right)$ at $37^{\circ} \mathrm{C}$. After being cultured for $3 \mathrm{~h}$, the bacteria were washed and the solutions were diluted to $50 \mu \mathrm{L}$. Then, $10 \mu \mathrm{L}$ of the diluted solution was taken and placed on agar plates. Colonies were counted visually after incubating for $24 \mathrm{~h}$ at $37^{\circ} \mathrm{C}$. The antibacterial rate was calculated using the following equation: $A=\left(C_{\mathrm{t}}-C_{0}\right) / C_{\mathrm{t}} \times 100 \%$, where $C_{\mathrm{t}}$ 
represents the bacteria number of the experiment group and $C_{0}$ represents the bacteria number of the control group.

\section{Cell proliferation and morphology}

The cell proliferation was assessed using the widely used Cell Counting Kit CCK-8 (CCK-8, Dojindo Laboratories, Japan). ${ }^{32}$ In brief, mouse-derived fibroblast cells (L929, Cell Bank of the Chinese Academy of Sciences, Shanghai, China) were propagated in 1640 Medium (PAA, Germany) supplemented with 10\% fetal bovine serum (FBS, Life Technologies, Gibco, USA). The BCC composites were placed in 48-well plates and sterilized using $\mathrm{Co}_{60}$-gamma radiation. After pretreatment with the culture medium for $12 \mathrm{~h}$, the cells were seeded at a density of $2.0 \times 10^{4}$ cells per well and cultured for $1 \mathrm{~d}, 3 \mathrm{~d}$ and $5 \mathrm{~d}$. At the determined time points, the CCK-8 working solution (1640: CCK-8 = $10: 1$ ) was added to each sample, which was then incubated at $37^{\circ} \mathrm{C}$ for $1 \mathrm{~h}$. Subsequently, the supernatant medium was extracted and the absorbance of $450 \mathrm{~nm}$ light was measured with a microplate reader (Thermo 3001, USA) $(n=5)$.

A laser scanning confocal microscope (CLSM, Leica SP8, Germany) was used to observe the cell viability and morphology of the L929 cells on the composites. Specifically, the obtained BCC and BCC-H membranes were placed in 48-well plates after having been sterilized using $\mathrm{Co}_{60}$-gamma radiation. $\mathrm{L929}$ cells were seeded on the membranes at a density of $2.0 \times 10^{4}$ cells per well and inoculated at $37{ }^{\circ} \mathrm{C}$ in an incubator with $5 \% \mathrm{CO}_{2}$. After being cultured for $1 \mathrm{~d}$, the samples were washed in PBS and then a living/dead staining solution was added for $20 \mathrm{~min}$ at room temperature. Thereafter, the cells were washed again with PBS. Finally, the cell viability and morphology of the L929 cells on the surface of the materials was observed using the laser scanning confocal microscope.

\section{Statistical analysis}

A one-way analysis of variance (ANOVA), followed by Tukey's test for comparison of means, was used to assess the level of significance, by employing the SPSS 19.0 statistics software. The results were expressed as the mean \pm standard error and $* p<$ 0.05 or $* * p<0.01$ was designated as statistically significant.

\section{Results and discussion}

\section{Infrared analysis of the $\mathrm{BCC}-\mathrm{H}$ composites}

In this study, the bacterial cellulose/collagen-hydroxypropyltrimethyl ammonium chloride chitosan composite (BCC-H) was synthesized by combining solution impregnation with the EDC/NHS chemical crosslinking method. In order to identify if HACC was introduced into the BCC material successfully, FTIR analysis was conducted to characterize the functional group changes of the BCC composites before and after recombination with HACC. The results (Fig. 1) showed that a new absorption peak was present for the BCC-H composites. Besides, the intensity of the absorption peak was enhanced when the HACC content increased, which demonstrated that HACC was incorporated into the BCC material successfully.

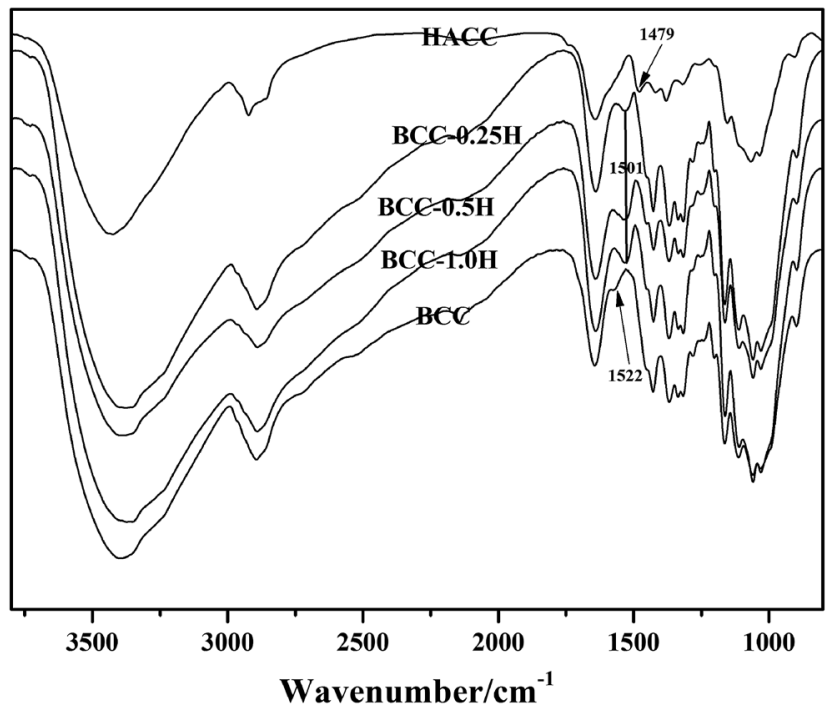

Fig. 1 FTIR spectra of the BCC, HACC and BCC-H composites.

\section{Surface morphology of the BCC-H composites}

The surface morphologies and structures of the BCC and BCC-H composites were also investigated using SEM to further validate the successful incorporation of HACC. As shown in Fig. 2, the BCC composites clearly showed a three-dimensional fibrous network structure. Compared to the BCC composites, the surface and section morphology of the BCC-H composites was different due to the immersion in the HACC solution. As can be seen in Fig. 2a-d, there was no difference between the surface morphologies of BCC and BCC-0.25H. However, when the HACC content increased, the surface morphology of the BCC-H composites showed a significant change and the BCC-1.0H composite was covered with a layer of HACC particles, which were distributed uniformly on the surface of the bacterial cellulose (Fig. 2d). Furthermore, the cross-section morphology showed that the interlayer distance also changed when the amount of HACC that penetrated into BCC increased (Fig. 2e-g). It was noted that the BCC-H composites showed a more fluffy layered structure compared to BCC when the HACC content increased, which may be facilitated by adhesion and grown into the materials. ${ }^{9}$ Therefore, from the SEM results, we can conclude that HACC was incorporated into the BCC composites successfully and this resulted in the changes in the structure of the BCC composites.

\section{Water absorptivity}

It has been the consensus that a good implanted biomaterial should not expand in volume excessively after absorbing water, so that it possesses stable physical and chemical properties. Besides, the shrinking of materials is an important factor resulting in the recurrence of hernias. ${ }^{33}$ In this study, the water absorptivity of the BCC-H composites was determined in PBS at $37^{\circ} \mathrm{C}$ and the water absorption curves of the BCC-H composites are shown in Fig. 3. The results showed that a balanced water absorption was reached quickly after immersing BCC-H in PBS 

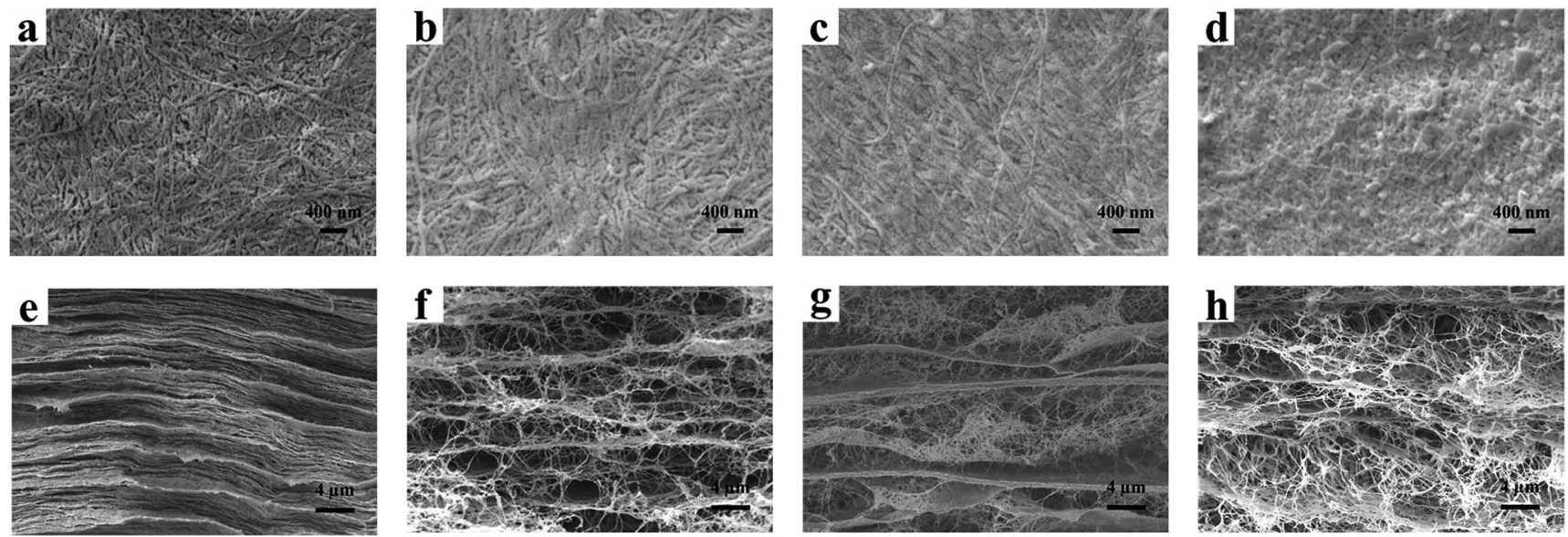

Fig. 2 SEM images of the BCC and BCC-H composites. The surface morphology (a-d) and the cross-sectional morphology (e-h) of BCC (a, e), $B C C-0.25 \mathrm{H}(b, f), B C C-0.5 \mathrm{H}(\mathrm{c}, \mathrm{g})$ and $\mathrm{BCC}-1.0 \mathrm{H}(\mathrm{d}, \mathrm{h})$.

for $30 \mathrm{~min}$, which demonstrated that the BCC-H composites that we fabricated possessed a good water absorptivity ability. Furthermore, compared with the BCC composites, the equilibrium moisture content of the BCC-H composites increased when the HACC content increased (Fig. 3b). For instance, the equilibrium moisture content of BCC-1.0H improved by almost $50 \%$ compared with BCC. The possible reasons may be that the hydration ability of the molecules was strengthened because of the introduction of quaternary ammonium salt groups into chitosan..$^{22}$ In addition, we also see that the volumes of BCC- $0.25 \mathrm{H}$ and $\mathrm{BCC}-0.5 \mathrm{H}$ in the water equilibrium state presented no significant difference, which contributes to their use as implantable materials. Nevertheless, for $\mathrm{BCC}-1.0 \mathrm{H}$, the volume expansion was obvious, which means that it may not be suitable as a good implantable biomaterial.

\section{Mechanical test}

Elastic deformation is one of the major parameters of artificial hernia meshes. ${ }^{34}$ It is reported that the natural abdominal wall possesses good elasticity and about $38 \%$ elastic deformation under $32 \mathrm{~N} \mathrm{~cm}^{-1}$ tension. $^{34}$ Therefore, similar elastic deformability should be required of an artificial mesh for hernia repair. Here, we studied the mechanical properties using a dynamic biomechanical testing machine and the results are shown in Fig. 4. Athough when compared with BC, the elongation at break of BCC was significantly increased, it still needed to be further enhanced for use as an artificial mesh. As is shown in Fig. $4 \mathrm{a}$, the elongation at break of the BCC composites greatly increased after immersing them in HACC solution. With increasing the content of HACC solution, the elongation at break of the BCC-H composites was also enhanced. However, contrary to the elongation at break, the corresponding tensile strength of the BCC-H composites showed the opposite change (Fig. 4b). The results showed that the tensile strength of the BCC-H composites decreased as the HACC content increased. As shown in Fig. 4, the elongation at break of $\mathrm{BCC}-0.5 \mathrm{H}$ (close to $38 \%$ ) and tensile strength $(25 \mathrm{MPa})$ can match the clinical requirements.

\section{Antibacterial studies}

At present, artificial hernia meshes in clinical applications are always associated with infections..$^{5,6}$ In this study, we try to develop a novel antibacterial hernia mesh by the addition of
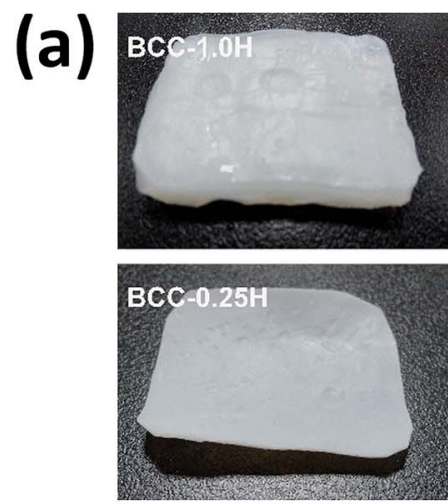
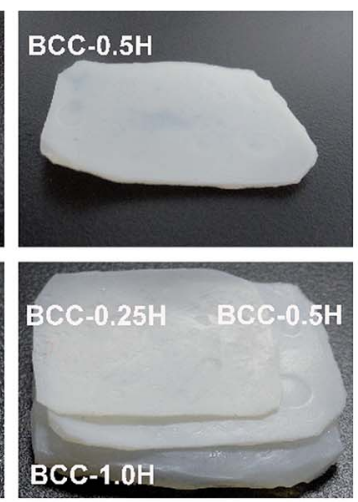

(b)

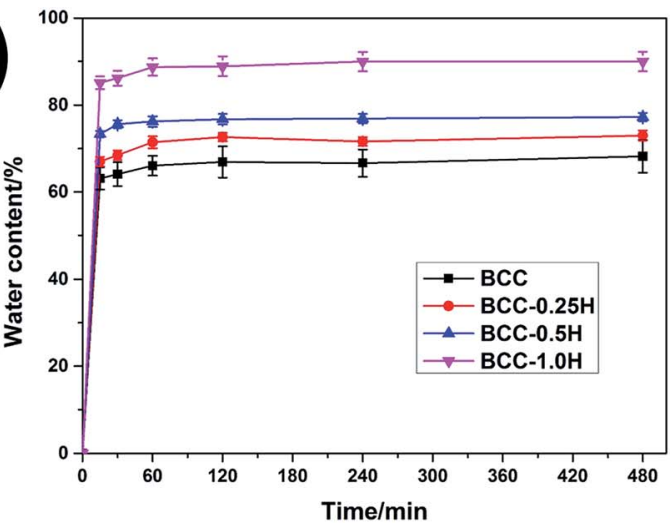

Fig. 3 Water adsorption of the BCC-H composites with differing content of HACC. (a) Swelling images of the BCC-H composites in the state of equilibrium. (b) Sorption curves of the BCC-H composites. 
(a)

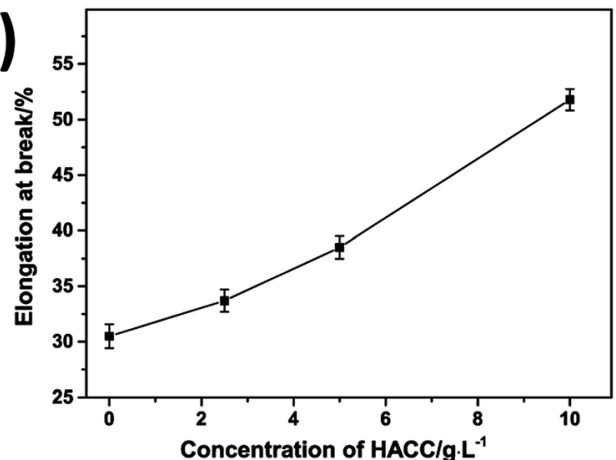

(b)

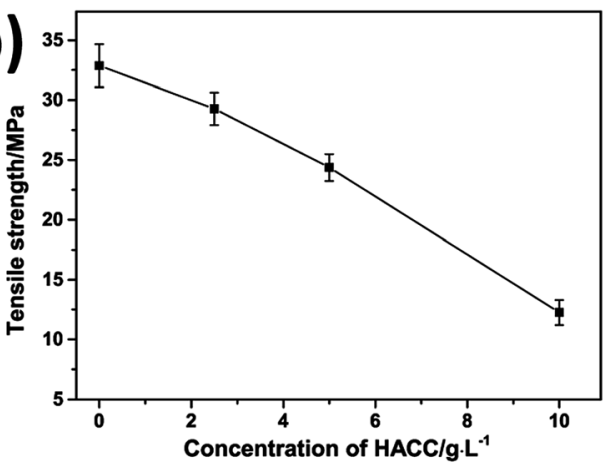

Fig. 4 Mechanical test of the BCC-H composites. (a) The effect of the HACC content on the elongation at break. (b) The effect of the HACC content on the wet tensile strength.

HACC into BCC composites. In order to verify its ability, the antibacterial efficacy of BC, BCC and BCC-H against E. coli and $S$. aureus was measured. As is shown in Fig. 5, the BCC-H composites showed a better antibacterial effect than the $\mathrm{BC}$ and BCC composites, while the BC and BCC composites have no antibacterial ability (Fig. 5a-c). Moreover, with increasing HACC content, the BCC-H composites have increased antibacterial efficacy against $E$. coli and $S$. aureus (Fig. 5d). Contrary to the BCC-H composites, the increasing number of bacterial colonies for the BCC composites may result from the collagen on the surface of the material, which helped the bacteria to adhere to the material's surface. To characterize this observation in a quantitative manner, the number of bacterial colonies was calculated for the BC, BCC and BCC-H composites. The results (Fig. $5 \mathrm{~b}$ and $\mathrm{c}$ ) showed that the bacteriostatic rates of BCC $-1.0 \mathrm{H}$ and $\mathrm{BCC}-0.5 \mathrm{H}$ reached up to $99 \%$ and $88 \%$, respectively. Besides, we also compared the antibacterial efficacy against $E$. coli and $S$. aureus among the BCC-H composites (Fig. 5d). It was obvious that the antibacterial efficacy of the BCC-H composites was enhanced when the content of HACC (a)
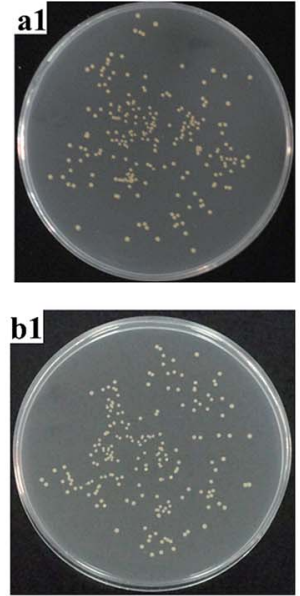

(b)

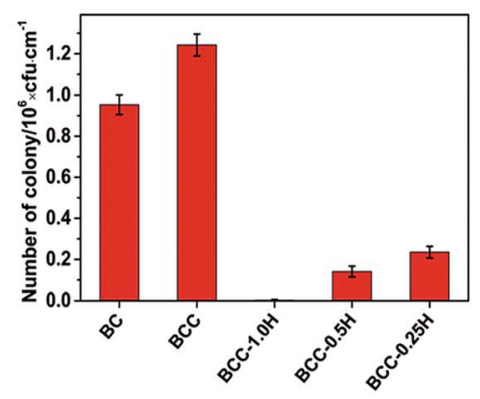

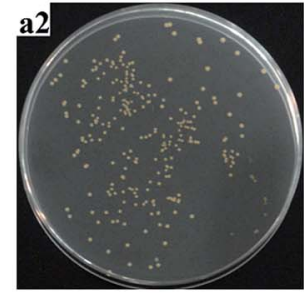

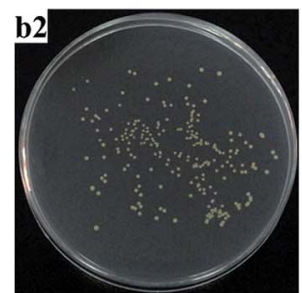

(c)
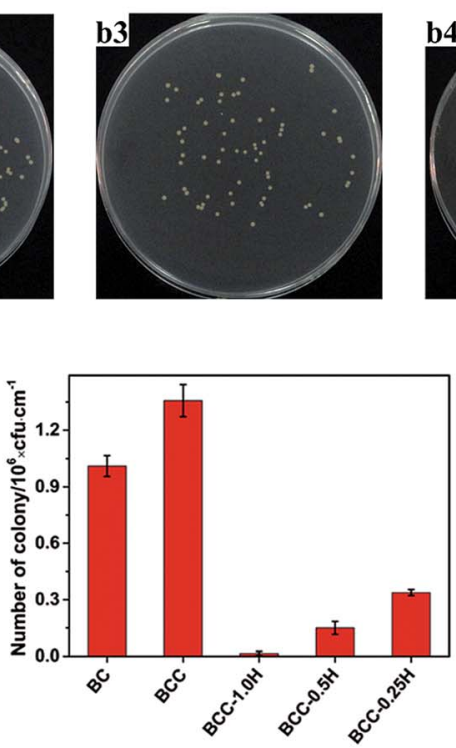
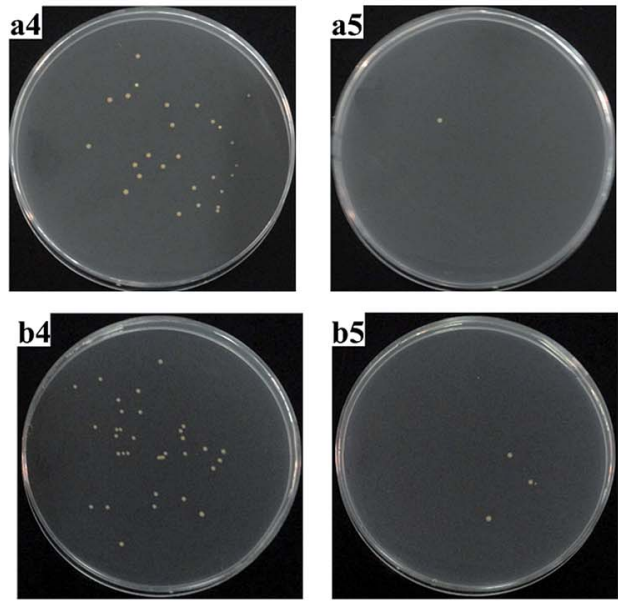

(d)

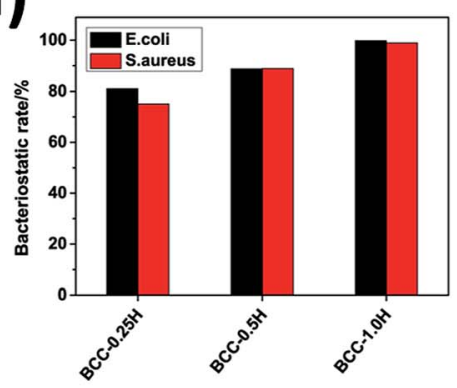

Fig. 5 (a) Antibacterial efficacy of BC, BCC and BCC-H against E. coli (a1-a5) and S. aureus (b1-b5). (a1 and b1) BC, (a2 and b2) BCC, (a3 and b3) $\mathrm{BCC}-0.25 \mathrm{H}$, (a4 and b4) BCC-0.5H and (a5 and b5) BCC-1.0H. Antibacterial effect of BC, BCC and BCC-H against E. coli (b) and S. aureus (c). (d) Antibacterial ratio of $\mathrm{BCC}-\mathrm{H}$ against $E$. coli and $\mathrm{S}$. aureus. 

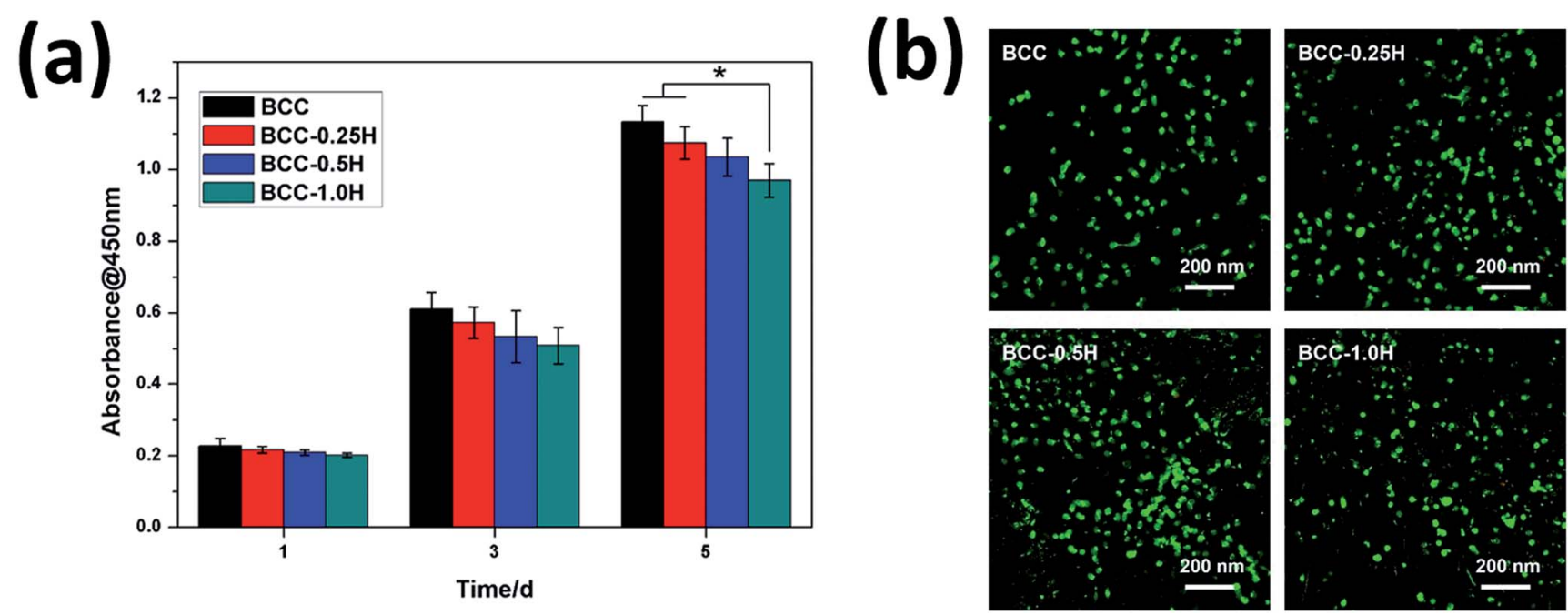

Fig. 6 Proliferation and morphology of $\mathrm{L} 929$ cells seeded on BCC and BCC-H. (a) Cell proliferation behavior measured by CCK- 8 assay after culturing $\mathrm{L} 929$ cells on BCC and BCC-H for 1,3 and $5 \mathrm{~d}$. (b) Cell morphology observed by laser scanning confocal microscopy after culturing L929 cells on BCC and BCC-H for $1 \mathrm{~d}$.

increased. In addition, we can also see that the antibacterial effect of BCC- $0.25 \mathrm{H}$ against $E$. coli and $S$. aureus was different. Previous works showed that the antibacterial effect of BCC-H composites against $E$. coli is better than that against $S$. aureus, which may be related to the different cell wall structures of Gram-negative bacteria and Gram-positive bacteria. The cell wall of Gram positive bacteria possesses a thicker peptidoglycan layer and can prevent more antibacterial agent from entering the cytoplasm to destroy the cellular structure..$^{35}$

\section{Cytotoxicity and biocompatibility}

Cytotoxicity and biocompatibility are the important parameters for artificial hernia meshes to be applied in clinic. ${ }^{34}$ To characterize the cytotoxicity and biocompatibility, L929 cell proliferation on BCC and BCC-H composites was assessed via CCK-8 assay after 1, 3, and 5 days of culturing. As shown in Fig. 6a, the L929 cells show normal cell proliferation on all samples. On the $1^{\text {st }}$ day, there was no difference between the cell densities on the BCC and BCC-H composites. With prolonged culture time (the $3^{\text {rd }}$ day), although the cell density on the BCC-H composites decreased gradually with increased content of HACC, there was no difference among them. On the $5^{\text {th }}$ day, BCC-1.0H still presented the lowest cell proliferation rate. Although the rate of cell proliferation of $\mathrm{BCC}-0.5 \mathrm{H}$ was still less than that of $\mathrm{BCC}$, there were no significant differences among $\mathrm{BCC}-0.5 \mathrm{H}$ and BCC. Besides, after culturing the L929 cells on BCC and BCC-H for $1 \mathrm{~d}$, live/dead staining was also carried out to ensure cell viability and adhesion. As is shown in Fig. 6b, the L929 cells possessed good cell adhesion and growth on the BCC and BCC-H composites. In addition, there were few dead cells after culturing for $1 \mathrm{~d}$, which demonstrated that the BCC and BCC-H composites showed no obvious cytotoxicity. With the culture time extended (the $5^{\text {th }}$ day), BCC- $1.0 \mathrm{H}$ and $\mathrm{BCC}-0.5 \mathrm{H}$ showed low cytotoxicity, which may result from the slow releasing of HACC from the BCC-H composites. These data indicate that, with the increase of HACC content in the BCC-H composites, the proliferation and cell viability of the L929 cells were not affected greatly, which demonstrated that the BCC-H composites possess good cell proliferation and biocompatibility.

\section{Conclusions}

In summary, we successfully fabricated novel BCC-H composites with differing HACC content by incorporating collagen and quaternary ammonium chitosan with BC, and explored their potential for hernia mesh application. A series of property characterizations were performed in detail. Our results showed that the $\mathrm{BCC}-\mathrm{H}$ composites, especially $\mathrm{BCC}-0.5 \mathrm{H}$, possess appropriate mechanical properties, and good antibacterial efficacy and biocompatibility, which prove them to be excellent candidates for artificial meshes in hernia surgery.

\section{Acknowledgements}

The authors would like to give sincere acknowledgement to the financial support provided by the National Natural Science Foundation of China (51273072, 51673071 and 51232002), Natural Science Foundation of Guangdong Province (2016A030313509), Guangdong Scientific and Technological Project (2014B090907004) and Guangzhou Important Scientific and Technological Special Project (201508020123).

\section{Notes and references}

1 A. W. Robbins and I. M. Rutkow, Surg. Clin. North Am., 1998, 78, 1007-1023.

2 L. Spangen, R. Andersson and L. Ohlsson, Am. Surg., 1988, 54, 574-577.

3 M. S. Sajid, S. A. Bokhari, A. S. Mallick, E. Cheek and M. K. Baig, Am. J. Surg., 2009, 197, 64-72. 
4 S. Sauerland, M. Walgenbach, B. Habermalz, C. M. Seiler and M. Miserez, Cochrane Database of Systematic Reviews, 2011, (3), CD007781.

5 K. LeBlanc, Hernia, 2001, 5, 135-138.

6 S. R. Steele, P. Lee, M. J. Martin, P. S. Mullenix and E. S. Sullivan, Am. J. Surg., 2003, 185, 436-440.

7 J. R. DeBord, Surg. Oncol. Clin., 1998, 78, 973-1006.

8 D. W. Hamer-Hodges and N. B. Scott, Journal of the Royal College of Surgeons of Edinburgh, 1985, 30, 65-67.

9 L. F. Li, L. Ren, L. Wang, S. Liu, Y. R. Zhang, L. Q. Tang and Y. J. Wang, RSC Adv., 2015, 5, 25525-25531.

10 S. Yamanaka, K. Watanabe, N. Kitamura, M. Iguchi, S. Mitsuhashi, Y. Nishi and M. Uryu, J. Mater. Sci., 1989, 24, 3141-3145.

11 H. Yamamoto and F. Horii, Macromolecules, 1993, 26, 13131317.

12 U. Udhardt, S. Hesse and D. Klemm, Macromol. Symp., 2005, 223, 201-212.

13 S. Hesse and T. Kondo, Carbohydr. Polym., 2005, 60, 457-465. 14 H. Jia, Y. Y. Jia, J. Wang, Y. Hu, Y. Zhang and S. R. Jia, in Proceedings of the 2009 2nd International Conference on Biomedical Engineering and Informatics, ed. R. Shi, W. J. Fu, Y. Q. Wang and H. B. Wang, 2009, Vol. 1-4, pp. 1138-1142.

15 K. Watanabe, M. Tabuchi, Y. Morinaga and F. Yoshinaga, Cellulose, 1998, 5, 187-200.

16 D. Klemm, D. Schumann, U. Udhardt and S. Marsch, Prog. Polym. Sci., 2001, 26, 1561-1603.

17 G. Helenius, H. Backdahl, A. Bodin, U. Nannmark, P. Gatenholm and B. Risberg, J. Biomed. Mater. Res., Part A, 2006, 76, 431-438.

18 A. Svensson, E. Nicklasson, T. Harrah, B. Panilaitis, D. L. Kaplan, M. Brittberg and P. Gatenholm, Biomaterials, 2005, 26, 419-431.

19 M. Zaborowska, A. Bodin, H. Backdahl, J. Popp, A. Goldstein and P. Gatenholm, Acta Biomater., 2010, 6, 2540-2547.
20 H. Bäckdahl, G. Helenius, A. Bodin, U. Nannmark, B. R. Johansson, B. Risberg and P. Gatenholm, Biomaterials, 2006, 27, 2141-2149.

21 R. A. A. Muzzarelli and F. Tanfani, Carbohydr. Polym., 1985, 5, 297-307.

22 V. A. Spinelli, M. C. M. Laranjeira and V. T. Fávere, React. Funct. Polym., 2004, 61, 347-352.

23 Z. L. Shi, K. G. Neoh, E. T. Kang and W. Wang, Biomaterials, 2006, 27, 2440-2449.

24 C. Q. Qin, Q. Xiao, H. R. Li, M. Fang, Y. Liu, X. Y. Chen and Q. Li, Int. J. Biol. Macromol., 2004, 34, 121-126.

25 C. Xu and C. Lu, Chin. J. Appl. Chem., 1996, 13, 94-96.

26 Y. Lin, Q. B. Lin, Z. Jiang, W. Zhang and X. U. Chen, Chin. J. Appl. Chem., 2002, 19, 351-354.

27 X. Wang, C. You, X. Hu, Y. Zheng, Q. Li, Z. Feng, H. Sun, C. Gao and C. Han, Acta Biomater., 2013, 9, 7822-7832.

28 X. Zhao, Y. Liu, W. Li, K. Long, L. Wang, S. Liu, Y. Wang and L. Ren, Mater. Sci. Eng. C, 2015, 55, 201-208.

29 L. C. S. Maria, A. L. C. Santos, P. C. Oliveira, A. S. S. Valle, H. S. Barud, Y. Messaddeq and S. J. L. Ribeiro, Polimeros, 2010, 20, 72-77.

30 B. Ma, Y. Huang, C. Zhu, C. Chen, X. Chen, M. Fan and D. Sun, Mater. Sci. Eng. C, 2016, 62, 656-661.

31 W. Hu, S. Chen, X. Li, S. Shi, W. Shen, X. Zhang and H. Wang, Mater. Sci. Eng. C, 2009, 29, 1216-1219.

32 H. C. Gao, H. Dong, X. D. Cao, X. L. Fu, Y. Zhu, C. B. Mao and Y. J. Wang, Langmuir, 2015, 31, 6797-6806.

33 P. K. Amid, A. G. Shulman, I. L. Lichtenstein, S. Sostrin, J. Young and M. Hakakha, J. Biomed. Mater. Res., 1994, 28, 373-375.

34 K. Junge, U. Klinge, A. Prescher, P. Giboni, M. Niewiera and V. Schumpelick, Hernia, 2001, 5, 113-118.

35 Q. L. Feng, J. Wu, G. Q. Chen, F. Z. Cui, T. N. Kim and J. O. Kim, J. Biomed. Mater. Res., 2000, 52, 662-668. 